\title{
EFFECT OF HEALTH EDUCATION ON LONG LASTING INSECTICIDAL NETS UTILIZATION AMONG MOTHERS OF UNDER FIVE CHILDREN IN YAMALTU DEBA LGA, GOM BE STATE, NIGERIA
}

\author{
${ }^{1}$ A bubakar JD, ${ }^{2}$ U mar AA, ${ }^{2}$ G obir AA, ${ }^{1}$ M ohammed A
}

${ }^{1}$ Department of Community Medicine, College of Medical Sciences, Gombe State University, Gombe State Nigeria

${ }^{2}$ Department of Community Medicine, Faculty of Clinical Sciences, A hmadu Bello University, Zaria Kaduna State Nigeria

Correspondences and reprint request to A uthor: : D r Abubakar Joshua Difa,

Department of Community Medicine, College of Medical Sciences, Gombe State University, PMB 127, Gombe, Gombe State Nigeria

Email: joshdifa41@gmail.com Tel: +2348096432540, A buja, Nigeria

\begin{abstract}
Background: Malaria remains a major global public health challenge. It is the leading cause of death among children below the age of five years and constitutes $10 \%$ of the continent's disease burden. The objective of this study was to determine effect of health education on utilization of long lasting insecticidal nets (LLINS) among mothers of under five children in Yamaltu Deba LGA of Gombe state: $\mathbf{O}$ bjective: This study was aimed at determining the effect of health education on LLIN s utilization among mothers of under five children in Yamal tu Deba LGA of Gombe State. M ethod: The study was a community-based quasi-experimental intervention where 240 mothers of under five children were selected from two communities using a multi stage sampling technique. Health education was given in the study community and withheld in the control community. Data was collected from both communities before and after the intervention using an interviewer administered structured questionnaire. Data was analyzed using EPI-INFO 3.7.1 and Micro soft Excel software. Result obtained was presented using proportion, Chi-squaretest was used to assess the relationship between categorical variables and decision taken at $p<0.05$. Results: The mean ages of respondents in study and control communitieswere $28.9 \pm 6.2$ and $27.9 \pm 6.7$ years respectively. Atpre-intervention, LLIN ownership was found to be $86.6 \%$ and $76.3 \%$ whileits utilization was $45.4 \%$ and $38.1 \%$ in both communities. After health education intervention, (LLINs) improved significantly in study community from $42.9 \%$ to $89.9 \%$ compared with control community which increased from $33.9 \%$ to $60.9 \%$ and the difference was statistical ly significant $(P=0.0001)$. Concl usion: This study concludes that health education significantly improved utilization. We recommendedcontinuous health education on LLIN sutilization in communities especially among mothers of under fivechildren.
\end{abstract}

Key words: Malaria, Long lasting insecticidal nets, Utilization, Yamaltu

\section{INTRODUCTION}

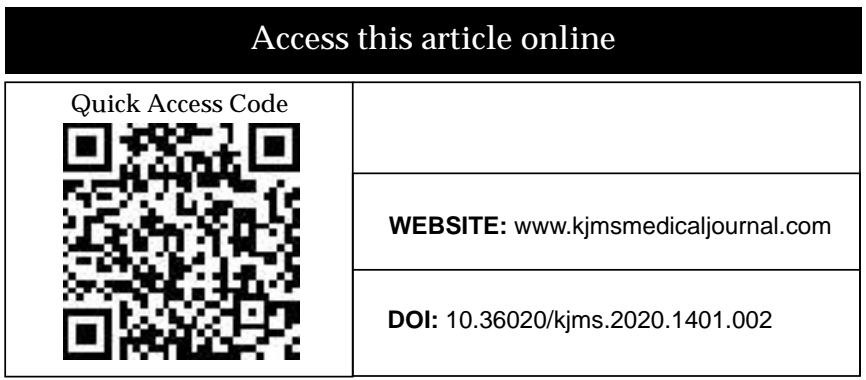

Malaria is caused by infection of red blood cells with protozoan parasites of the genus plasmodium inoculated in to thehuman host by a feeding female anophilinemosquito. ${ }^{1}$

Malaria remains a major global public health challenge. It is the leading cause of death among children bel ow the age of fiveyears and constitutes 
$10 \%$ of the continent's disease burden. ${ }^{2}$ In 2015 alone, about 212 million cases and 429,000 deaths were recorded globally. Across Africa, many people lack access to basic tools they need to prevent malaria. ${ }^{3}$ The use of Long Lasting Insecticidal Nets (LLINs) and Indoor Residual Spraying (IRS) has been very effective in reducing the prevalence of malaria in many countries over the years ${ }^{4,5}$ and the two interventions are the mainstay in the control of vector of malaria thereby reducing the rate of its transmission ${ }^{6}$ However, use of long lasting insecticidal nets is the most promising among the various components adopted in thecontrol of malaria. ${ }^{7-10}$

The World Health Organization (WHO) in 2007 reviewed its policy on LLINs to include all population at risk. Sincetheyear 2000, use of LLINs has been shown to reduce incidence of malaria by $50 \%$ and on average about 5.5 lives can be save per 1000 vulnerablegroups' i.e. pregnant women across all transmission settings. ${ }^{11,12}$ In sub-Saharan A frica, it is estimated that, $53 \%$ population at risk slept under an LLIN in 2015. The proportion of people sleeping inside LLINs is generally close to proportion with access to LLINs. Insecticides treated nets were introduced in Nigeria as an effective means of preventing mosquito bites and malaria transmission following the 2000 Abuja target of $60 \%$ LLIN scoverage. ${ }^{13}$

Despite high number of LLINs distributed in Nigeria over theyears, the utilization rate has been very low. Previous studies have shown that, only $16 \%$ of households owned at least one LLIN and less than $5 \%$ of pregnant mothers utilized them. ${ }^{14},{ }^{15}$ However, there has been a rise in LLIN s ownership and utilization in the country as a result of free LLINs distribution across the country. The 2015 Malaria Indicator Survey showed an appreciable increase of $69 \%$ in LLINs ownership among household population nationally and $38 \%$ of de facto population slept insidean LLIN a night before the survey. ${ }^{16} \mathrm{M}$ alaria contributes to high burden of infections in theN orth Eastern states of the country. Hospital-based study indicated a prevalence of $49.2 \%$ and $58.3 \%$ among under five children attending clinics in Gombe and Adamawa States respectively. ${ }^{17}{ }^{18}$ Insecticides treated net ownership in Gombe State was as high as $87 \%$ but utilization was $34 \% .{ }^{14}$ Of recent, there has been a decrease in the trend of malaria prevalence nationally from $42 \%$ in 2010 to $27 \%$ in 2015 , this could be due to increase in utilization of insecticidal nets wherethe nets usage increased from $6 \%$ in 2010 to $44 \%$ in $2015 .{ }^{16}$ Some of the reasons for poor utilization of long lasting insecticidal nets were: heat (42\%), non availability of the nets (13\%), itching (9\%), bad smell (6\%) and LLIN s not big enough (4\%). ${ }^{16}$ Other studies showed poor awareness, poverty and indifference as some of the reasons for poor LLIN utilization. ${ }^{16,}{ }^{19}$ Evidence suggest that, malaria prevention and treatment choices are affected by knowledge of the problem. ${ }^{20} \mathrm{~A}$ review of the trend of malaria over the years, shows that increase in LLINs utilization and not ownership plays an important role in decreasing the prevalence of malaria.Theobjective of thestudy was to determine the effectiveness of health education on LLINs utilization in the study area. The outcome of this would help strengthen LLIN utilization among pregnantmothers.

\section{MATERIALS AND METHOD \\ Study area}

The study was carried out in Yamaltu Deba Local Government A rea of GombeState, Nigeria between the months of March 2018 to June 2018. The experimental study was conducted in Morom community in Yamaltu Deba Local Government Area with a projected population of 12,000 from 2006 census while the control study was conducted in Bula Community in Akko Local Government Area with a projected population of 13,000 from 2006 census.

\section{Study design}

A community based quasi experimental study

\section{Study Population}

All mothers of under five children living in Morom and Bulacommunities at thetimeof thestudy

\section{Inclusion criteria}

Mothers of under five children living with their children in Morom and Bula communities for more than sixmonths

\section{Exclusion criteria}

Mothers of under five children on transit or vacation in thestudy area 


\section{Sample size determination}

The minimum sample size for each community was determined using the formula:

$\mathrm{n}=\left[1 /(1-\mathrm{f}) \times 2 \times(Z ?+Z \mathrm{Z}) \times \mathrm{P} \times(1-\mathrm{P}) /\left(\mathrm{Po}_{0} \mathrm{P}_{1}\right)\right]^{29}$

Where $\mathrm{n}=$ Minimum sample size per group

$\mathrm{P}=\left(\mathrm{Po}+\mathrm{P}_{1} / 2\right)$

$\mathrm{Po}=$ Proportion of mothers who slept inside an LLIN a night before the survey in Gombe State during 2013 National Demographic Health Survey $=34 \%{ }^{28}$

$\mathrm{P}_{1}=$ Estimate of expected proportion of mothers who slept under insecticide treated net after the health education intervention $=49 \%$ i.e. an increase of $15 \%$ from $(34 \%-49 \%)$

$Z$ ? =Standard Normal Deviate at 95\% Confidence Interval $=1.96$

$Z ß=S t a n d a r d \mathrm{~N}$ ormal Deviate of $80 \%$ Power i.e 0.84

$\mathrm{f}=\mathrm{N}$ on-response rate $=10 \%=0.1$

$\mathrm{P}=\mathrm{Po}_{\mathrm{P}} \mathrm{P}_{1} / \mathrm{L}=0.34+0.49 / 2=0.83 / 2=0.415 \sim 0.42$

$P=0.42$

$1-P=0.58$

$n=\left[1 /(1-f) \times 2 \times(Z ?+Z B) 2 \times P \times(1-P) /\left(P o-P_{1}\right)\right]^{2} .{ }^{29}$

$\mathrm{n}=1 /(1-0.1) \times 2 \times(1.96+0.84) 2 \times 0.42 \times 0.58 /(0.34-0.49) 2$

$\mathrm{n}=4.24 / 0.0225$

$\mathrm{n}=188.4$

$\mathrm{n} \approx 189$

$\mathrm{n}, 189$ being the minimum sample size was however increased to 240 to recruit more respondents who were willing to participate for the benefit of free LLINs at pre-intervention. Therefore, each group had 240 samples.

\section{Sampling M ethod}

Multistage sampling technique was employed for this study. In the first stage, of the 11 Local Government Areas (LGAs) in Gombe State, Yamaltu Deba and Akko LGAs were selectedpurposively as experimental and control LGA respectively. At the second stage, Difa-LuboKinafa ward was selected from the 11 wards of Yamaltu Deba LGA while Bula ward was selected from the 11 wards of Akko LGA using simple random sampling (SRS) technique by balloting. In the third stage M oron community from Difa-LuboKinafa ward and Bula community from Bula ward were selected through SRS by balloting. In the fourth stage, the existing household PHC numbering was used to select households and respondents were selected from the households until the required sample size was achieved. In a household with more than one mother/ caregiver with under five children only one of them was selected for the interview. Same method was applied for the selection of mothers in the control community.

\section{D ata collection}

Selected mothers were interviewed using a semi structured interviewer administered questionnaire by trained research assistants, study was piloted at Doho community in Kwami LGA, 50 kilometres from the study area and corrections were effected where gaps were discovered. A base line survey was conducted to assess LLINs ownership and utilization in both the intervention and control communities. Health education was given to the selected mothers in the experimental community for a period of threedays. Six classes were used each consisting of 40 mothers per class per session, two sessions were conducted daily where didactic lectures, role play and demonstration of long lasting insecticidal; types of nets, ways of hanging nets and the benefits of using nets was done. Long lasting insecticidal nets were distributed to all participants in both the experimental and control communities. The only difference in intervention was health education which was given to the experimental community only while it was withheld in thecontrol community.

Three months after intervention, respondents were interviewed to determine the effect of health education on LLINs utilization in both the experimental and control communities using the same data collection tools and research team, as pre-intervention survey.

\section{Data A nalysis}

All data generated at baseline and postintervention was processed and analyzed using EPI INFO 3.7.1 and Microsoft Excel Software. Sociodemographic data were presented as percentages while quantitative data were described using means and standard deviation. Chi-Squaretest was used to determine any association between certain 
variables and outcome of intervention among mothers. A confidence interval of $95 \%$ was used in this study and P-value of $\varangle 0.05$ was considered significant.

\section{Ethical Consideration}

Ethical approval was sought from the Gombe State Ministry of Health Ethical Committee. Permission was obtained from the Chairman of Yamaltu Deba and A kko LGAs respectively. Verbal consent was obtained from mothers of under-five before administering thequestionnaires,

\section{RESULTS}

Four hundred and sixty-eight respondents of 474 werestudied at post intervention (238 from M orom and 230 from Bula communities), giving a response rate of $98.7 \%$. Of the 474 mothers recruited for the survey at pre-intervention, 468 (98.7\%) of them responded at Post-intervention. The age group 2529 years old has the highest number of respondents in Morom 80 (33.6\%) and Bula 75 (31.8\%). Those above the age of 40 years in Morom $2(0.8 \%)$ and Bula $3(1.3 \%)$ constituted the least among the respondents at pre-intervention. The mean age for Morom and Bula communities were $28.9 \pm 6.2$ and $27.9 \pm 6.7$ years respectively. Majority of the respondents in Morom 190 (78.8\%) and Bula 200 $(84.7 \%)$ were Muslims. There was low literacy level among the respondents in both communities, the proportion of those who attended only Primary school and those with no formal education in Morom and Bula was 136 (57.1\%) and 142 (60.2\%) respectively. Thesocio demographic characteristics were similar and comparable from both communities and observed differences were not statistically significant. (Table1)
Table 1: Socio-demographic characteristics of respondents at pre-intervention

\begin{tabular}{|c|c|c|c|c|}
\hline Characteristics & \multicolumn{4}{|c|}{ Community } \\
\hline \multicolumn{5}{|c|}{ Morom $=238$ Bula=236 } \\
\hline $\begin{array}{l}\text { Age } \\
\text { (Years) }\end{array}$ & up Freq (\%) & Freq $(\%)$ & 3.459 & 0.6301 \\
\hline $15-19$ & $14(5.9)$ & $18(7.6)$ & & \\
\hline $20-24$ & $28(11.8)$ & $37(15.7)$ & & \\
\hline $25-29$ & $80(33.6)$ & $75(31.8)$ & & \\
\hline $30-34$ & $56(23.5)$ & $54(22.9)$ & & \\
\hline $35-39$ & $40(16.8)$ & $30(12.7)$ & & \\
\hline $40+$ & $20(8.4)$ & $22(9.3)$ & & \\
\hline Religion & & & 1.9623 & 0.1613 \\
\hline Christianity & $48(20.2)$ & $36(15.3)$ & & \\
\hline Islam & $190(78.8)$ & $200(84.7)$ & & \\
\hline $\begin{array}{l}\text { Educational } \\
\text { Status }\end{array}$ & & & 0.4476 & 0.5039 \\
\hline None/ Primary & $136(57.1)$ & $142(60.2)$ & & \\
\hline Sed Tertiary & $102(42.9)$ & $94(39.8)$ & & \\
\hline Occupation & & & 5.401 & 0.1450 \\
\hline Farming & $54(22.7)$ & $46(19.5)$ & & \\
\hline Trading & $82(34.5)$ & $64(27.1)$ & & \\
\hline Civil Service & $12(5.0)$ & $14(5.9)$ & & \\
\hline None & $90(37.8)$ & $112(47.5)$ & & \\
\hline M arital Status & & & 2.152 & 0.142 \\
\hline Married & $221(92.9)$ & $210(89.0)$ & & \\
\hline Divorce/ Widow & $17(7.1)$ & $26(11.0)$ & & \\
\hline
\end{tabular}

Ownership of LLIN was found to bevery high in Morom (86.6\%) and Bula (76.1\%) communities at base line. The proportion of respondents who slept inside an LLIN a night before the survey in Morom and Bula was $45.4 \%$ and $38.1 \%$ respectively. Therewas no statistically significant difference when the intervention groups were compared on LLIN ownership. $(P=0.110)$ Majority of respondents in Morom 168 (72.4\%) and Bula 195 (88.6\%) got their LLINs from the village Primary Health Centres, only $9.5 \%$ and $2.7 \%$ in Morom and Bula purchased LLIN s from the market. When the intervention groups were compared on source of LLIN at pre-intervention, there was a statistically significant difference. 
$(\mathrm{P}<0.01)$. Respondents gave different reasons why they did not sleep inside an LLIN night before the survey. (Table2)

Table 2: Reasons for notsleeping insidea net by the respondents at pre-intervention

\begin{tabular}{lccc}
\hline Reasons & $\begin{array}{c}\text { Intervention G roup } \\
\text { M orom (\%) }\end{array}$ & $\begin{array}{c}\text { Control G roup Total (\%) } \\
\text { Bula (\%) }\end{array}$ \\
\hline Heat & $51(37.5)$ & $76(48.7)$ & $127(43.5)$ \\
Itching & $9(6.6)$ & $12(7.7)$ & $21(7.2)$ \\
Difficulty & $14(10.3)$ & $12(7.7)$ & $26(8.9)$ \\
Breathing & & & \\
Difficulty & $25(18.4)$ & $20(12.8)$ & $45(15.4)$ \\
H anging & & & \\
N o reason & $37(27.2)$ & $36(23.1)$ & $73(25.0)$ \\
\hline Total & $\mathbf{1 3 6 ( 1 0 0 )}$ & $\mathbf{1 5 6 ( 1 0 0 )}$ & $\mathbf{2 9 2 ( 1 0 0 )}$ \\
\hline
\end{tabular}

$?^{2}=4.725, P=0.317, d f=4$

At post-intervention, theproportion of respondents who slept inside LLIN a night before the survey in Morom as a result of health education increased from $45.4 \%$ to $89.9 \%$ and the difference was statistically significant $(P<0.01)$. In Bula community, where health education was withheld, despite an increased from $38.1 \%$ to $62.6 \%$ the differencewas not statistically significant. $(P=0.110)$ (Table3).

Table 3: Utilization of LLIN samong study and control groups atpre-intervention and post-intervention

\begin{tabular}{lcccc}
\hline \multicolumn{2}{c}{ Pre-intervention } & \multicolumn{2}{c}{ Post-intervention } \\
Yes (\%) & No (\%) & Yes (\%) & No (\%) \\
& & & & \\
\hline M orom (Study) & $108(45.4)$ & $130(54.6)$ & $214(89.9)$ & $22(10.1)$ \\
Bula (Control) & $90(38.1)$ & $146(61.9)$ & $144(62.6)$ & $86(37.4)$ \\
\hline$?^{2}=2.556, P=0.110, d f=1$ & & $?^{2}=51.54, P=0.001, d f=1$
\end{tabular}

\section{DISCUSSION}

The proportion of respondents who own nets at the time of survey in Morom and Bula were $86.6 \%$ and $76.3 \%$ this finding was similar to the 2015 Malaria Indicator Survey in which the percentage of household who owns ITNs was $87 \%$ but finding was contrary to similar studies conducted among mothers in Southern Ethiopia (15.8\%), Ghana (57.2\%) and Ibadan Nigeria (44.2\%) where nets ownership waslower in all study areas. ${ }^{16,22,30,}$
Respondents who slept under a net a night before the survey evidenced by net hanging on their beds (defacto) in Morom and Bula was $45.4 \%$ and $38.1 \%$ respectively. Similar findings were obtained in other studies assessing net utilization during pregnancy among mothers in Ibadan (31.6\%), Enugu (39.1\%) and the 2015 Malaria Indicator Survey in GombeState(34\%). TheN igerian Malaria Indicator Survey 2015 found a higher percentage of $55 \%$ in defacto population who slept under LLIN at the national level. This higher value could be due regional differences as the southern states recorded higher values compared to the northern region where this study was carried out. Other studies in Ogun State Nigeria and Southern Ethiopia found $75 \%$ and $73.3 \%$ of women who slept under an LLIN night before survey. This could be due todifference in literacy level where it is higher in areas recording high level of LLINs utilization. However, another study in Ijebu-Ode, Ogun Statefound only $28.5 \%$ of net utilization among nursing mothers which was lower than our findings. $16,21,23,27$,

One of the targets set at the Abuja summit April 2000 was to have $60 \%$ of population at risk sleeping under insecticide treated nets by 2015 . To achieve this, LLINs need to be made available, affordable and most importantly, improving its utilization. In this study area, and many other areas across A frica, LLIN s were madeavailableand accessible through free community and ante natal clinics distribution however, nets utilization has remained very low. In this study area, the Abuja target of $60 \%$ net utilization, among population at risk has not been achieved despite huge investment by Global Fund, World Bank Malaria Booster Project and the Presidential Malarialnitiative.

Respondent's source of information on LLIN, source of nets and reasons why respondents do not sleep under nets are some of the factors that influence respondent's ability to use LLIN. This study found $84.9 \%$ and $68.7 \%$ of respondents in Morom and Bula respectively who said their source of information on LLIN was from the village health clinics. Similarly, a study conducted to assess knowledge, attitude and practice on malaria and ITN utilization among pregnant mothers in Southern Ethiopia found $96.5 \%$ of respondents who 
reported they received information from health clinics precisely by a Community Health Worker. Contrary to the above findings, the Malaria Indicator Survey 2015 found radio to be the main source of information in $70 \%$ of the respondents at thenational level and $91 \%$ of respondentsin Gombe State. ${ }^{16}$ Despite the fact that radio is the most commonly used medium of communication in the study area, this study found radio to be the least source of information on LLIN. This study and others showed the importance of health education communication at heal th facilities especially during antenatal visits and routineimmunization services. Long lasting insecticidal nets ownership was found to be high in this study as $86.6 \%$ and $76.3 \%$ of respondents in Morom and Bula owned an LLIN at pre-intervention. This finding was similar to a study conducted in Ogun StateN igeria. ${ }^{13}$ but higher than other studies in North Eastern Nigeria and Ghana. ${ }^{20,}{ }^{22}$ In this study, more than $75 \%$ of respondents in Morom and Bula communities got their LLINs from clinics; this was contrary to another study conducted in Southern Ethiopia where $99 \%$ of respondents indicated free community distribution as source of their nets. ${ }^{21}$ Since net ownership does not guarantee utilization, respondents give different reason why they did not sleep inside LLIN night before the survey. In Morom and Bula almost half of respondents said discomfort due to heat was the reason why they did not sleep inside nets. While others complained of Itching, difficulty in hanging nets at night, about a quarter give no reason at all. The 2015 Malaria Indicator survey and another study in middle belt Ghana found similar result, contrary to a study in southern Ethiopia where $69.9 \%$ of respondents said they did not sleep under net because there were no mosquitoes. ${ }^{16,21,22}$ Heat could be a limiting factor to LLIN utilization, this study was conducted in March through Juneduring the peak of dry season and onset of rains where extremetemperaturesarerecorded.

Prevalence of LLIN utilization among respondents in intervention community has increased from $45.4 \%$ to $89.9 \%$ while control community recorded an increase from $38.1 \%$ to $62.6 \%$, the difference in LLIN utilization was statistically significant when the two communities were compared. Various studies across Africa, to determine effect of health education on net utilization found health education a very important tool in motivating mothers to use LLINs at home. A study in Ogun State, Nigeria recorded an increase in insecticidal nets utilization from $29.5 \%$ to $72.6 \%$, another study in Jos, Nigeria recorded an increase from $4.6 \%$ to $88.4 \%$, other studies found an increase of $28.8 \%$ to $89.6 \%$ and $19.2 \%$ to $82.2 \%$ in Enugu, Nigeria and Sudan respectively. Findings in intervention communities were statistically significant compared with the control communities. ${ }^{23-26}$

This study shows a statistically significant increase in utilization of LLIN s after heal th education in the intervention community. However, net utilization did not improve significantly in the control community where health education was withheld. Factors that may influence the use of LLINs have been related to cost and availability of LLIN s. ${ }^{23} \mathrm{H}$ owever, this study found other factors like heat and poor understanding of the benefits of LLINs responsible for low utilization of LLINs among participants.

\section{Limitations}

It would have been much easier to administer the questionnaires in English, but majority of the respondents do not understand English but use Tera and Fulani as medium of communication. To avoid passing inappropriate messages to the respondents, research assistants were trained to minimizeerrors that may ariseduring interview.

\section{CONCLUSION}

This study concludes that, LLIN s ownership does not guarantee their utilization, it however proved that health education significantly improved LLIN utilization among respondents. We recommend health education especially targeting mothers of under fivechildren in thecommunities. 


\section{REFERENCES}

1. World Health Organization (WHO): Guidelines for the Treatment of malaria. Clinical malaria and Epidemiology 3rd Ed 2015. A vailable from www.who.int.iris.bitstream/ health. Assessed 3rd February 2018

2. Ezeigbo OR, Ejike EN, Nwachukwu I. Insecticidetreated nets: ownership and usage in the control of malaria in A bia State, Nigeria. AmJ Epid and Infect Diseases. 2016; 4(3): 42-46.

3. World Health Organization (WHO). World Malaria Report 2016. Available from www.who.int.malaria.publication/ world-malariareport-2016/ report/ en. Accessed 4th February 2018.

4. Mabaso ML, Sharp B, Langeler C. Historical review of malaria control in southern Africa with emphasis on the use of indoor residual spraying. Trop Med Int Health, 2004; 9 (8):846-856. A vailable from doi.10.1111/ j.1365-3156.2004.01265.

5. Apinjoh TO, Anchang-Kimbi JK, Mugri RN, Tangoh DA, Nyingchu RV, Chi KF, et al. Effect of insecticides treated nets on Plasmodiumfalciparum infection in rural and semi-urban communities in the South West Region of Cameroon. Public Lib Sci Med, 2015; 10(2): e0116300.

6. Pluess B, Tenser FC, Lengeler C, Sharp BL. Indoor residual spraying for preventing malaria. Cochrane Database of Systematic Review, 2010; 1(4):3.

7. Worall E, Basu S, Hanson K: Is malaria a disease of poverty? A review of the literature. Tropical Medicine and. Int Health, 2005; 10(10): 1047-1057.

8. Killean GF, Smith TA, Ferguson HM, Mshinda $\mathrm{H}$, A bdulla S, et al. Preventing childhood malaria in Africa by protecting adults from mosquitoes with Insecticide treated nets. Public LibSci Med 2007; 4(7):1247.

9. Curtis CF and MnzaraAP. Comparism of house spraying and insecticide treated nets for malaria control. Bull World Health Organization, 2009; 78(12):1385-1400.

10. Mullian J, Yukich J and Hanson K. Cost and effects of the Tanzania national voucher schemefor insecticidetreated nets. MalariaJ , 2008; 7(32):2.

11. Langeler $C$. Insecticide treated nets and curtains for preventing malaria. CochraneDatabase Syst Review 2004; (2):CD00363. A vailable from http:/ / www.ncbc.nm.nih/ pubmed/ 15106149

12. Roll Back Malaria Partnership. Contribution of malaria control to maternal and newborn. Progress and Impact Series. 2014; 1(10): 74.

13. Ogunsanmi $O$, Essang $A$, Olaoye $T$, Solademi A, and Makinde B. Insecticides treated nets usage and barriers among pregnant women attending antenatal clinic in Ogun State, Nigeria. Euro Sci Jour, 2016; 12(30):1857-7881.

14. United Nations: Millennium development goals report. New York, United N ations. 2008; 1 (5): 2. A ccessed 3rd February 2018.

15. National Population Commission (NPC), ICF. N igeria Demographicand H ealth Survey 2008. A buja Nigeria: Calverton Maryland, USA; 2009. pp 201.

16. Federal Ministry of $\mathrm{Health}(\mathrm{FMOH})$. Nigeria malaria indicator survey: Final Report National Malaria Elimination Programme 2015. pp 55.

17. Lamogo $\mathrm{Y}$, Yoriyo KP. A retrospective survey of malaria prevalence in under five age group: A case study of kaltungo General Hospital Gombe State-Nigeria. Jour of Med and Biol Sci., 2013; 3(2): 136-142.

18. Kunihya IZ, Samaila AB, Nassai I, Sarki A and Haruna MY. Prevalence of malaria infection among children attending specialist Hospital Yola, Adamawa State Nigeria. Jour of Med and Biol Sci Res, 2016; 2(8): 136-142.

19. Adeneye $A K$, Jegede DS, Mafe $M$, Nwokocha EE. A pilot study to evaluate malaria control strategies in Ogun State, Nigeria. World Health Population, 2007; 9(2): 83-94.

20. Ibrahim SM, Umar NI, Garba NA, Isa B, Usman HA, Bako BG. Utilization of insecticides treated nets among pregnant women attending ante-natal dinic in suburban referral Hospital, North East Nigeria. BMJ \& MR, 2014; 4 (12): 23432351.

21. Teklemariam Z, Awolle A, Dessie $Y$, Weldegebreal F. Ownership and utilization of insecticides treated nets for malaria control in Harari National Regional State. Eastern Ethiopian Pan Afr Med J, 2015; 21(52) doi.10.11604

22. Manu G, Boamah-Kaali EA, Febir LG, Ayipah E, Owusu-Agyei S, Asante KP. Low utilization of insecticides treated nets among 
pregnant women in Middle Belt of Ghana. Malaria impact in enhancing utilization of ITN among restreat, 2017; ID 7481210 pp 7 Available from: mothers of under five in rural North Sudan: an https:/ / doi.org/ 10.1155/ 2017/ 7481210. experimental study. MalariaJ, 2016; 15(509): 5.

23. Amoran OE, FatugaseKO, Fatugase OM, 27. Ugwu EO, Ezechukwu PC, Obi SN, Ugwu AlausaKO.Impact of health education intervention AO, Okeke TC. Utilization of insecticide treated on insecticides treated nets uptake among nursing nets among pregnant women in Enugu, South mothers in rural communities in N igeria. BMC. Res. Eastern N igeria. Nig J Clin Pract. 2013; 16 (3): 29220125;444doi.10.10.1186/ 1756-0500-444 296.

24. Salako LA, Brieger WR, A folabi BM, Umeh 28. National Population Commission (NPC), RE, Agomo PU, Asa S. Treatment of childhood ICF. Nigeria Demographicand Health Survey 2013, fevers and illnesses in three rural Nigerian Abuja Nigeria: Rockville, Maryland, USA; 2014. pp communities. J. Trop. Paediatrics, 2001; 47(1):230- 192. 238.

29. AdebowaleSA. Sample Size Determination 25. Envuladu EA, Banwat ME, Lar LA, Miner $\mathrm{CA}$, Agbo HA, Zoakah Al. Effect of communitybased Intervention on awareness and utilization of long lasting insecticides nets in a rural area of Barkin Ladi LGA Plateau State Nigeria. J Med Res, 2012; 1(3): 29-33.

26. Elmosaad YM, Elhadi M, Khan A, Malik women in Shashogo District, Southern Ethiopia. EM, Mahmud E. Communication for behavioural MalariaJ, 2015; 14:235.

Cite this article as: Abubakar JD, Umar AA, Gobir AA, Mohammed, A., Effect of Health Education on Long Lasting Insecticidal N ets Utilization A mong M others of Under Five Children In Yamaltu Deba LGA, Gombe State, Nigeria. KJMS 2020; 14(1): 1 - 8. 